\section{Influence of Ventilatory Inefficiency over Exercise Capacity in Smokers and Patients with Pulmonary Emphysema: A Cross Sectional Study}

\section{Abstract}

Background: Increased VE/VCO means Ventilatory inefficiency to clear CO.

Objective: Determine the influence of Ventilatory inefficiency over exercise capacity in smokers and patients with pulmonary emphysema.

Methods: A cardiopulmonary stress test was performed in 56 patients. Influence of VE/VCO over Oxygen consumption (VO), Power (W) Breathing reserve (BR), expiratory flow limitation (EFL) and Inspiratory capacity (IC) were determined. Surrogate cardiac parameters Oxygen pulse and Circulatory power were also assessed.

Results: Patients with pulmonary emphysema, with spirometric severity corresponding to GOLD 1-3 (2011 classification), presented a rise in VE/VCO, with reduction in VO and W. Half of the patients presented dynamic hyperinflation. Linear regression showed a reduction of VO, $W$ and $B R$ related with the increased VE/VCO ( $p=0.001,0.000$ and 0.028$)$. Patients with VE/VECO $>34$, showed a reduction in Oxygen pulse and Circulatory power $(P=0.037$ and 0.019). In multiple regressions including the independent variables body mass index, $E F L$, IC and VE/VCO over VO and W, only VE/VCO demonstrated to be significant ( $P=0.034$ and 0.024).

Conclusion: Increased VE/VCO was seen in patients and was correlated with a decreased exercise capacity independent of hyperinflation on multivariate analysis. Patients with VE/ VCO over 34, presented a reduction of surrogate parameters of cardiac function.

Keywords: COPD; Emphysema; Exercise and lung function; Exercise testing; Ventilation
Iván R Caviedes ${ }^{1,2}$, Rodrigo Soto ${ }^{1,2}$ and Claudio Silva ${ }^{2,3}$

\author{
1 Service and Bronchopulmonary \\ Laboratory, Clínica Alemana de Santiago, \\ Chile \\ 2 Faculty of Medicine, German Clinic, \\ University of Development, Chile \\ 3 Department of Images, Clínica Alemana \\ de Santiago, Chile
}

Corresponding author: Iván R Caviedes

” icaviedes@alemana.cl

$\mathrm{MD}$, Service and Bronchopulmonary Laboratory, Clínica Alemana de Santiago, Chile and Faculty of Medicine, German Clinic, University of Development, Chile.

Tel: 6681920

Citation: Caviedes IR, Soto R, Silva C. Influence of Ventilatory Inefficiency over Exercise Capacity in Smokers and Patients with Pulmonary Emphysema: A Cross Sectional Study. Insights Allergy Asthma Bronchitis. 2016, 2:2.

Received: April 07, 2016; Accepted: November 25, 2016; Published: November 28, 2016

\section{Introduction}

During the last years emphasis has been placed on the importance of dynamic hyperinflation as a main factor limiting physical activity in patients with chronic obstructive pulmonary disease (COPD) [1-6]. Consequently, it could be assumed that patients with greater bronchial obstruction should exhibit greater limitations; however in clinical practice, patients with a lesser degree of obstruction may exhibit greater limitations. This behavior suggests the presence of multiple mechanisms involved.

Recently a renewed interest in Ventilatory inefficiency as a limiting factor on exercise capacity on COPD has been demonstrated. When the ratio of VE/VCO abnormally increases, this translates in to a Ventilatory inefficiency to clear CO (Figure 1). The understanding of this unbalanced ventilation is not simple and seems to depend on different mechanisms. VE/VCO may rise in parallel with physiological dead space and increase with deregulation of respiratory control, depending on increased central and peripheral chemo sensitivity and increased ergo receptor drive. Also a poor capacity of the right ventricle or impeded venous return to increase lung perfusion during exercise has been suggested [5-9].

These are familiar mechanisms involved in COPD, either as early lactic acidosis related with deconditioning. The result of these abnormal mechanisms is a disproportionate ventilatory requirement [5-8]. In COPD, where the increase in expiratory resistance causes a reduction of the expiratory time available for deflation, the increased ventilatory demand imposed for ventilatory inefficiency during exercise, boosts expiratory flow limitation. The greater the expiratory flow limitation, the 


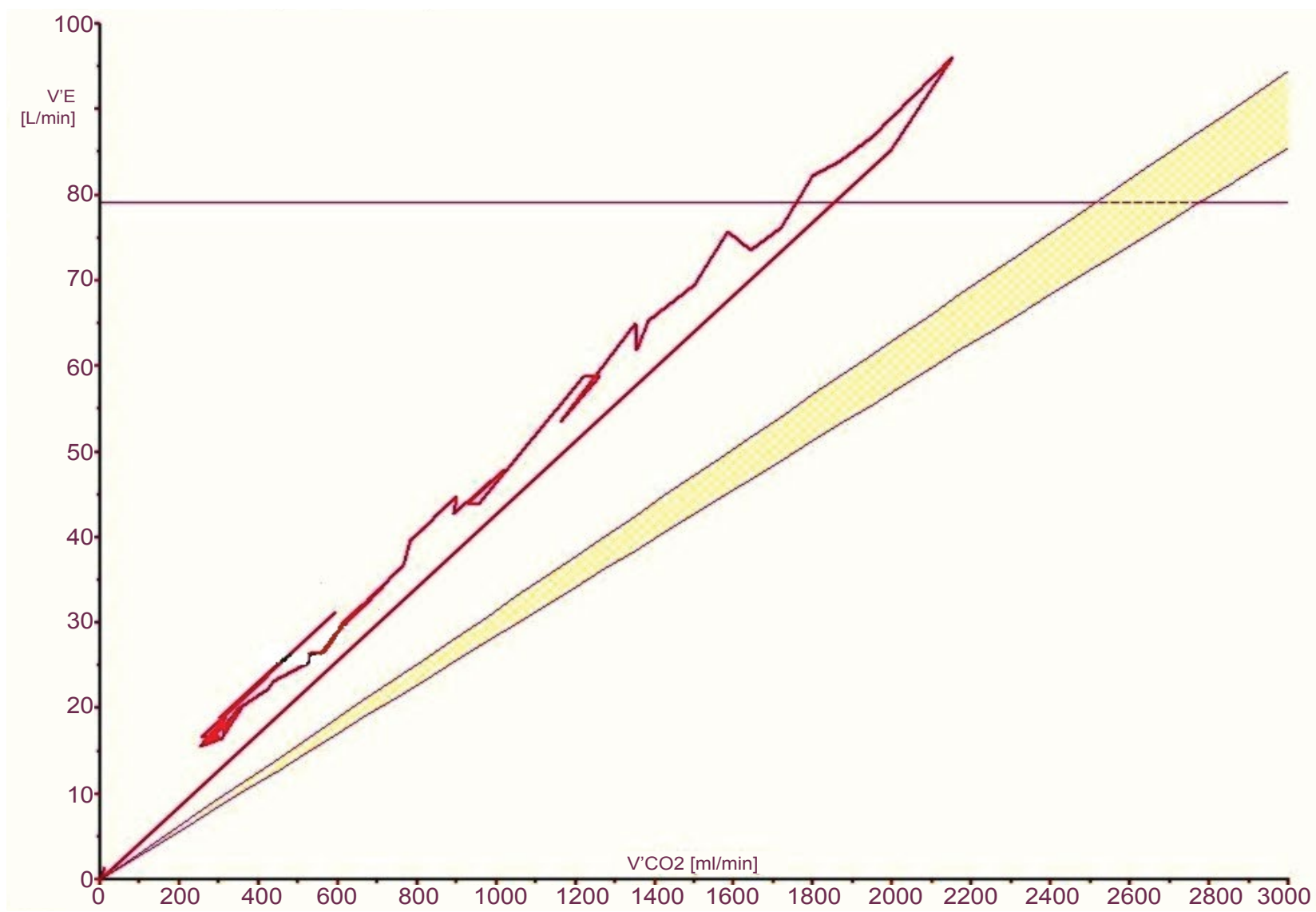

Figure 1 A 70-year-old patient with pulmonary emphysema with spirometric severity corresponding to gold 3: increase in the $\mathrm{CO}_{2}$ equivalent $\left(\mathrm{ve} / \mathrm{vcO}_{2}\right)$ due to ventilatory inefficiency. The curve presents a typical left-ward deviation compared with a normal reference shape.

greater the dynamic hyperinflation [1-7]. With an increase in the ventilatory demand to clear $\mathrm{CO}$, the breathing reserve decreases further during exercise. Limited information is available describing the influence of this mechanism on the physical capacity of patients with COPD at different FEV1 post bronchodilator grades as defined by Global Initiative for Chronic Obstructive Lung Disease (GOLD) in 2011, and information in smokers is scarse $[3,4,10]$. A preliminary report has previously been published by our group (5).

Hypothesis: Ventilatory inefficiency increases ventilatory requirement to clear $\mathrm{CO}$, boosts expiratory flow limitation and reduce breathing reserve. This effect increases in pulmonary emphysema, depending on the severity of COPD. Due to these mechanisms, ventilatory inefficiency limits exercise capacity.

Objectives: To quantify the magnitude of VE/VCO in smokers with normal spirometry, and patients with pulmonary emphysema with a spirometric severity corresponding to GOLD 1 to 3 [10], during a cardiopulmonary stress test, and to show that V/VCO translates into a limitation on exercise depending on the severity of COPD.

\section{Methods}

Cross sectional study in patients with pulmonary emphysema with mild to severe COPD, according to GOLD (2011 classification).
Study protocol was approved by our institutional review board and ethics committee, (Comité de Ética de la Investigación, Facultad de Medicina, Clínica Alemana, Universidad del Desarrollo), and all patients provided informed consent. Recruitment criteria have been presented previously in a preliminary report (5).

Smoker's individuals were active smokers ( $\geq 20$ pack/year) with normal spirometry. As was shown in our preliminary report (5), the entry criteria of patients were presence of pulmonary emphysema by computed tomography. We applied the radiological criteria defined by Foster et al. [11]: 1-2 mm well defined centrilobular holes in secondary pulmonary lobules without discernible wall, preserved anatomical borders of the secondary lobule, and predominant involvement in the upper lung zones.

All participants were in a non-acute phase of their disease and receiving a stable drug regimen. Participants had no coexisting medical conditions that would interfere with physiologic testing. Exclusion criteria included presence of cardiac disease in terms of the available information in the clinical record, or signs of cardiac hearth failure at physical examination, or leg claudication, which could limit exercise capacity.

Baseline pulmonary function tests consisted of spirometry and a CO diffusion test. Demographics and baseline pulmonary function 
tests of patients are presented in Table 1. An incremental cardiopulmonary stress test, with an increase of the workload of 10-15 Watts every minute, was performed according to the American Thoracic Society/American College of Chest Physicians guidelines [7,8,12]. A Jaeger Oxycon Pro equipment (Erich Jaeger, Höchberg, Germany) was used.

Reference values of Jones et al. for oxygen consumption (VO), Power (W) and Oxygen pulse (VO/heart rate) were applied $[13,14]$. Dyspnea and fatigue of the lower extremities were graded according to Borg scale. Reference values of VE/VCO and Breathing reserve (BR) were obtained of a control group of normal individuals.

In the study we recorded W, VO, and the ventilatory threshold, according to the $\mathrm{V}$-slope method $[7,8]$. As BR we use the equation

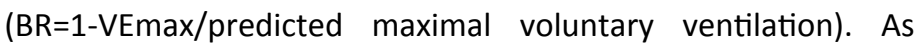
suggested for other authors, during exercise and considering the independence of voluntary effort at ventilatory threshold, we used the measured value of V/VCO at this level $[5,7,8,12]$.

Expiratory flow limitation (EFL) was determined by superimposing the flow/volume dynamic curve over the maximum expiratory flow-volume curve, and was calculated at the final work load of the test, plotting the volume with flow overlap over the tidal volume in the horizontal axis $[3,13,14]$. The value of EFL was expressed as a percentage. In each work load a forced inspiratory capacity was determined, and their decrease $(\Delta I C)$ was calculated by its difference between the beginning and the end of the exercise. $\Delta \mathrm{IC}$ was considered dynamic hyperinflation $[3,5,15,16]$.

The substitute parameters of cardiac function oxygen pulse (VO /heart rate) and circulatory power (CP) were measured at peak exercise. The $\mathrm{VO} /$ heart rate is a surrogate for the systolic volume by the Fick equation: $\mathrm{VO}=$ cardiac output $\times \Delta \mathrm{C}(\mathrm{a}-\mathrm{v}) \mathrm{O}$, and $\mathrm{CP}=\% \mathrm{VO}$ max $\times$ peak systolic blood pressure, is a surrogate for cardiac power (cardiac output $\times$ mean arterial pressure $\times$ K) [17-19].

\section{Statistical Analysis}

Prior to recruitment, sample size was estimated considering VE/ VCO as the principal variable. We used a design of comparison of means with an expected average difference of $20 \%$ compared to the normal value of VE/VCO. For this estimation we used the following suppositions: $\mathrm{Cl}$ of $95 \%$, and power of $99 \%$ ( $ß$ error of $10 \%)$, and one standard deviation of $25 \%$ compared to the mean of both samples. The minimum estimated sample accrual required was 33 patients.

A Statistical descriptive analysis was performed using Kolmogrov Smirnov test to evaluate normal distribution in the variables. Mean and standard deviation were calculated for normaldistributed variables and median and intercuartile range (IQR) in those with non-gaussian distribution.

A one-way ANOVA for comparison between groups was applied, using Levene test to evaluate homogeneity of variance. Post hoc analysis with Bonferroni correction was performed. Nonparametric variables were compared with Kruskall Wallis test.

The association between the independent continuous variable (V /VCO) and response continuous variables (VO, W, VO /heart rate, and $C P$ ) was assessed by bivariate linear regression with Bootstrap analysis.

Multiple regression models analyzing the independent variables VE/VCO, body mass index (BMI), EFL and $\triangle I C$, and their association over the dependent continuous variables: $\mathrm{VO}$ and $\mathrm{W}$ were constructed.

Sample size was calculated with software EPIDAT 3.1 (Dirección Xeral de Saúde Pública, La Coruña, España, http://www.sergas. es). Statistical analysis was performed with SPSS software, version 19.0 (SPSS, Chicago, Illinois) and P values $<0.05$ (Cl 95\%) were considered significant.

Table 1 Demographic characteristics and functional study at rest of the studied individuals: smokers with normal spirometry, and patients with pulmonary emphysema with spirometric severity corresponding to gold 1-3.

\begin{tabular}{|c|c|c|c|c|c|c|}
\hline & Controls & Smokers & Gold 1 & Gold 2 & Gold 3 \\
\hline N & 16 & 20 & 12 & 10 & 14 \\
\hline Age (years) & $63(53-82)$ & $59.5(50-71)$ & $69.5(40-74)$ & $68.5(49-80)$ & $64.5(53-79)$ \\
\hline Female (\%) & 50 & 45 & 25 & 50 & 29 & 0.056 \\
\hline Height (cm) & $164+/-8.19$ & $169.50+/-8.34$ & $168+/-4.24$ & $168.5+/-9.01$ & $176.5+/-11.48$ & 0.226 \\
\hline Weight (Kg) & $72+/-11.69$ & $72+/-13.56$ & $87+/-9.9$ & $72.5+/-9.67$ & $74.5+/-17.19$ & 0.332 \\
\hline BMI (kg/m) & $24.13+/-3.60$ & $27+/-4.50$ & $30.75+/-1.91$ & $26.6+/-2.47$ & $24.25+/-3.43$ & 0.255 \\
\hline FVC (\%) & $104.5+/-20.55$ & $104.9+/-14.85$ & $121.5+/-5.66$ & $88.4+/-12.03$ & $71.65+/-14.96$ & 0.000 \\
\hline FEV1 (\%) & $122+/-21.99$ & $96.7+/-13.79$ & $103.65+/-4.74$ & $57+/-4.3$ & $47+/-10.38$ & 0.000 \\
\hline FEV1/FVC (\%) & $83.5+/-4.44$ & $77.7+/-4$ & $67.6+/-0.85$ & $51+/-7.88$ & $42.2+/-7.14$ & 0.000 \\
\hline DLCO (\%) & - & $65+/-12.21$ & $77+/-9.9$ & $46.5+/-16.09$ & $45+/-9.27$ & 0.000 \\
\hline DLCO/VA & - & $73+/-12.65$ & $78+/-14.85$ & $50+/-15.25$ & $48+/-13.36$ \\
\hline
\end{tabular}

One way ANOVA comparing the different groups, and Levene test to evaluate homogeneity of variance. Values are presented as the mean +/- SD, and were expressed as percentage of predicted. P: P value between groups. No significant differences are shown in demographics, and significant differences are presented in functional study at rest.

BMI: body mass index, FVC: forced vital capacity, FEV1: forced expiratory volume in one second, DLCO: diffusing capacity, DLCO/VA: diffusing capacity for per unit of alveolar volume. 


\section{Results}

Fifty- six subjects were studied ( 35 men and 21 women), including 20 smokers with normal spirometry, and 36 patients with pulmonary emphysema with spirometric severity corresponding to GOLD 1-3, with a mean \pm SD age of $61.71 \pm 8.41$ y (range 40-82 y). Pulmonary emphysema was demonstrated by axial computed tomography. They did not have known cardiac disease and their resting electrocardiograms were normal.

A mean \pm SD of VE/VCO of $32.35 \pm 2.75$, and median IQR of BR of 44.50 (28.50-49.28\%) was obtained from a control group of 16 subjects. Demographic and functional characteristics are presented in Table 1.

Patients studied halted their exercise tests because of dyspnea and leg fatigue. Seven of them presented Oxygen saturation under $90 \%$ (mean \pm SD $82.76 \pm 5.81 \%$ ). Comparing smokers with normal spirometry, and patients with pulmonary emphysema with spirometric severity corresponding to GOLD 1-3, a decrease of VO max (mean \pm SD $88.64 \pm 16.25 \%$ to $59.57 \pm 16.89 \%$ ), and a decrease of $W$ (mean \pm SD $90.77 \pm 16.32 \%$ to $48.71 \pm 16.77 \%$ respectively) was observed. They also presented a decrease in $B R$ [median IQR 31 (15-47\%) to 0 (0-7.5\%)] (Table 2).

In smokers with normal spirometry, and patients with pulmonary emphysema, with spirometric severity corresponding to GOLD $1-3$, an increase in VE/VCO was demonstrated (mean \pm SD 32.97 \pm 3.63 to $39.22 \pm 5.74)$, along with EFL [median IQR 0 (0-31.25\%) to $87.5(75-100 \%)]$.

Twenty-eight patients presented dynamic hyperinflation with $\Delta \mathrm{IC}$ [median IQR of $0(0-0.10 \mathrm{ml})$ to $0.50(0.35-0.89 \mathrm{ml})] .30$ patients presented a severe increase in VE/VCO over 34 (mean \pm DS $39.74 \pm 4.24$ ). Results of the cardiopulmonary stress tests in smokers with normal spirometry, and patients with pulmonary emphysema, with spirometric severity corresponding to GOLD 1-3, are presented in Table 2.

Linear regression suggested that VE/VCO translate into exercise limitation in smokers with normal spirometry, and patients with pulmonary emphysema, with spirometric severity corresponding to GOLD 1-3 (Figure 2). Each unit of increase in VE/VCO decreased VO max by $-1.82 \%$ ( $95 \% \mathrm{Cl}-2.66$ to -0.98$)$, reduced $\mathrm{W}$ by $-2.94 \%$ (95\% Cl -3.91 to -1.80$)$, and decrease BR by $-1.32 \%(95 \% \mathrm{Cl}-2.29$ to -0.11$)(P=0.001,0.000$, and 0.028 , respectively) (Figure 3).

In relation to cardiocirculatory parameters, patients with a severe increase of VE/VCO over 34, reduced VO/heart rate by $-2.14 \%$ $(95 \% \mathrm{Cl}-3.80$ to -0.46$)$ and reduced $\mathrm{CP}$ by -557 units $(95 \% \mathrm{Cl}-931$ to -131$)$ for each unit of increase in VE/VCO ( $P=0.037$ and 0.019 , respectively) (Table 3).

In models of multiple regression including the influence of the independent variables $B M I, E F L, \triangle I C$, and VE/VCO, over the response continuous variables $\mathrm{VO}$ and $\mathrm{W}$, only the independent variable VE/VCO showed statistical significance $(P=0.034$ and 0.024) (Table 4).

\section{Discussion}

Ventilatory inefficiency is the final effect of an increase in the physiological dead space, deregulation of respiratory control, poor capacity of the right ventricle to increase lung perfusion, impeded venous return and early lactic acidosis. These characteristic mechanisms in pulmonary emphysema enhance the ventilatory requirement $[3,20-26]$. On the other side, expiratory flow limitation during exercise causes dynamic hyperinflation, enhances respiratory work and approximates the patient to respiratory fatigue [3-25]. During exercise there is strong evidence of the limitation imposed by dynamic hyperinflation, but only a few studies have evaluated the influence of ventilatory inefficiency [3-5].

Measured at ventilatory threshold the mean VE/VCO is about 25 in healthy young subjects, and near 30 in older individuals. Usually it is less than 32 . In our control subjects the mean \pm SD VE/VCO was $32.35+/-2.75$. Ventilatory inefficiency is considered when values overpass $34[3,27,28]$.

On the other side, normal BR has a wide normal range $[7,8]$, a median IQR of our control group was 44.50 (28.50 - 49.28\%). In

Table 2 Results of cpet in smokers with normal spirometry, and patients with lung emphysema with spirometric severity corresponding to gold 1-3.

\begin{tabular}{|c|c|c|c|c|c|}
\hline & Smokers & Gold 1 & Gold 2 & Gold 3 & $\mathbf{P}$ \\
\hline Dyspnoea (Borg score) & $4+/-1.82$ & $4+/-1.41$ & $5+/-1.62$ & $5+/-1.50$ & 0.043 \\
\hline Leg fatigue (Borg score) & $5+/-1.45$ & $2.5+/-0.71$ & $5+/-0.84$ & $4+/-1.6$ & 0.980 \\
\hline $\mathrm{VO}_{2} \max (\%$ predicted) & $88.64+/-16.25$ & $83.50+/-14.47$ & $80.80+/-18.24$ & $59.57+/-16.89$ & 0.000 \\
\hline $\mathrm{VO}_{2} \max / \mathrm{Kg}\left(\mathrm{mlO}_{2} / \mathrm{Kg}\right)$ & $21.63+/-7.05$ & $21.24+/-6.51$ & $16.81+/-3.87$ & $15.77+/-4.14$ & 0.019 \\
\hline Wmax (\% predicted) & $90.77+/-16.32$ & $85.63+/-7.41$ & $79.75+/-20.32$ & $48.71+/-16.77$ & 0.000 \\
\hline *BR (\%) & $31(15-47)$ & $17.5(14-26.75)$ & $10(0.75-22.5)$ & $0(0-7.5)$ & 0.001 \\
\hline *EFL(\%) & $0(0-31.25)$ & $56.25(25-75)$ & $75(55.75-86.5)$ & $87.5(75-100)$ & 0.000 \\
\hline$* \Delta I C(L)$ & $0(0-0.10)$ & $0(0-0.40)$ & $0.37(0.17-0.69)$ & $0.50(0.35-0.89)$ & 0.001 \\
\hline $\mathrm{VE} / \mathrm{VCO}_{2}$ & $32.97+/-3.63$ & $34.60+/-3.69$ & $39.03+/-5.42$ & $39.22+/-5.74$ & 0.001 \\
\hline $\mathrm{VO}_{2} /$ heart rate ( $\%$ predicted) & $101.64+/-18.24$ & $103.90+/-16.22$ & $89.75+/-14.20$ & $83.17+/-11.68$ & 0.006 \\
\hline $\mathrm{CP}\left(\% \mathrm{VO}_{2} \max \times \mathrm{PSBP}\right)$ & $14145+/-3745$ & $17094+/-3692$ & $16244+/-4035$ & $9842+/-3076$ & 0.000 \\
\hline
\end{tabular}

One way ANOVA comparing the different groups, and Levene test to evaluate homogeneity of variance. Values are shown as the mean +/- SD.

*Values shown as median IQR. P: P values between groups.

Significant differences were demonstrated on functional parameters at maximal exercise between groups.

$\mathrm{VO}_{2}$ max: maximum oxygen consumption, $\mathrm{VO}_{2} \mathrm{max} / \mathrm{Kg}$ : $\mathrm{VO}_{2}$ max per $\mathrm{Kg}$ of weight, Wmax: maximum Power, BR: breathing reserve, EFL: expiratory flow limitation, $\triangle \mathrm{IC}$ : decrease in Inspiratory Capacity, $\mathrm{VO}_{2}$ /heat rate: Oxygen pulse, $\mathrm{CP}$ : Circulatory power, PSBP: peak systolic blood pressure. 


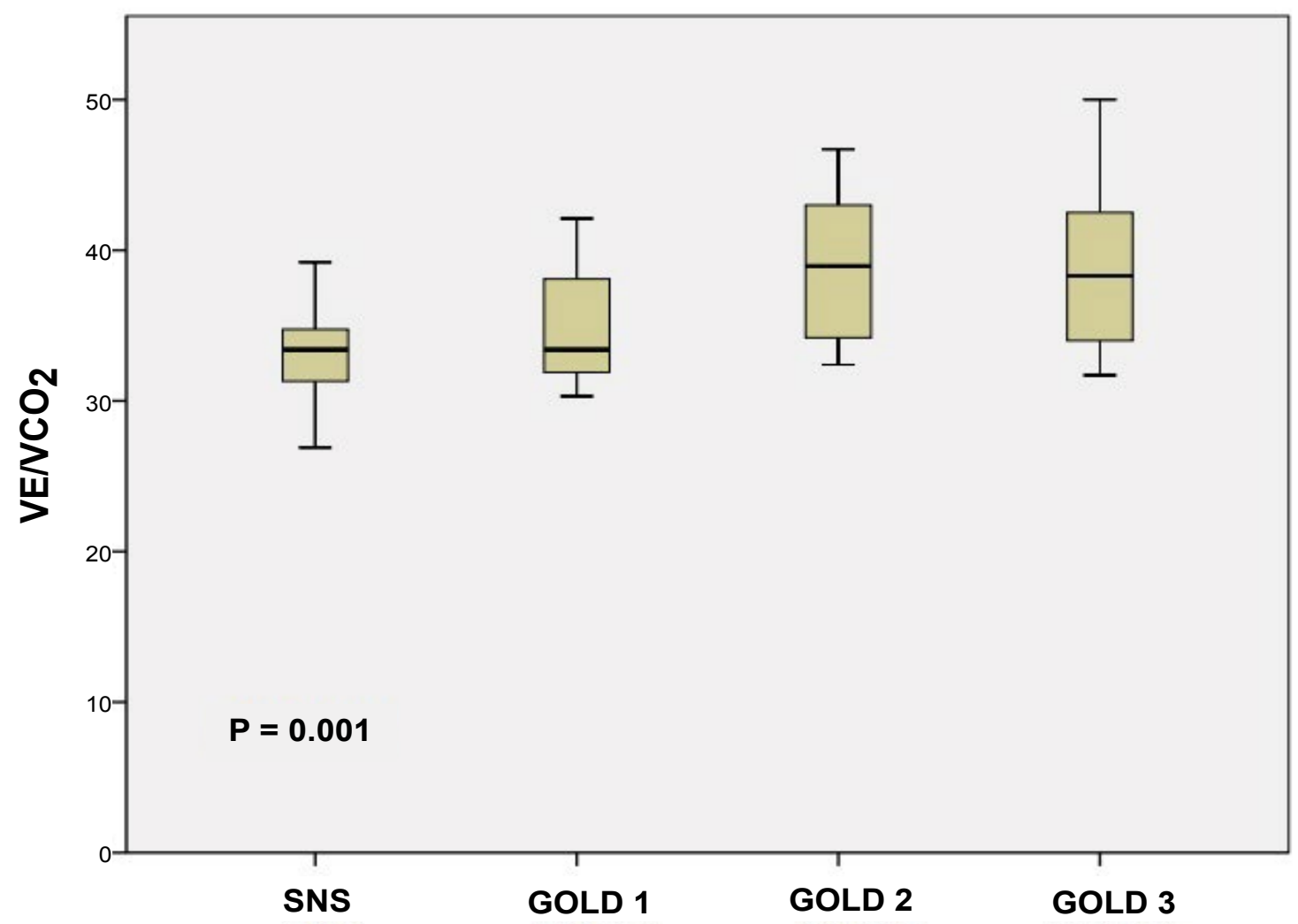

Figure 2 Descriptive statistics of $\mathrm{ve} / \mathrm{vCO}_{2}$ in smokers with normal spirometry, and patients with pulmonary emphysema with spirometric severity corresponding to gold 1- 3 .

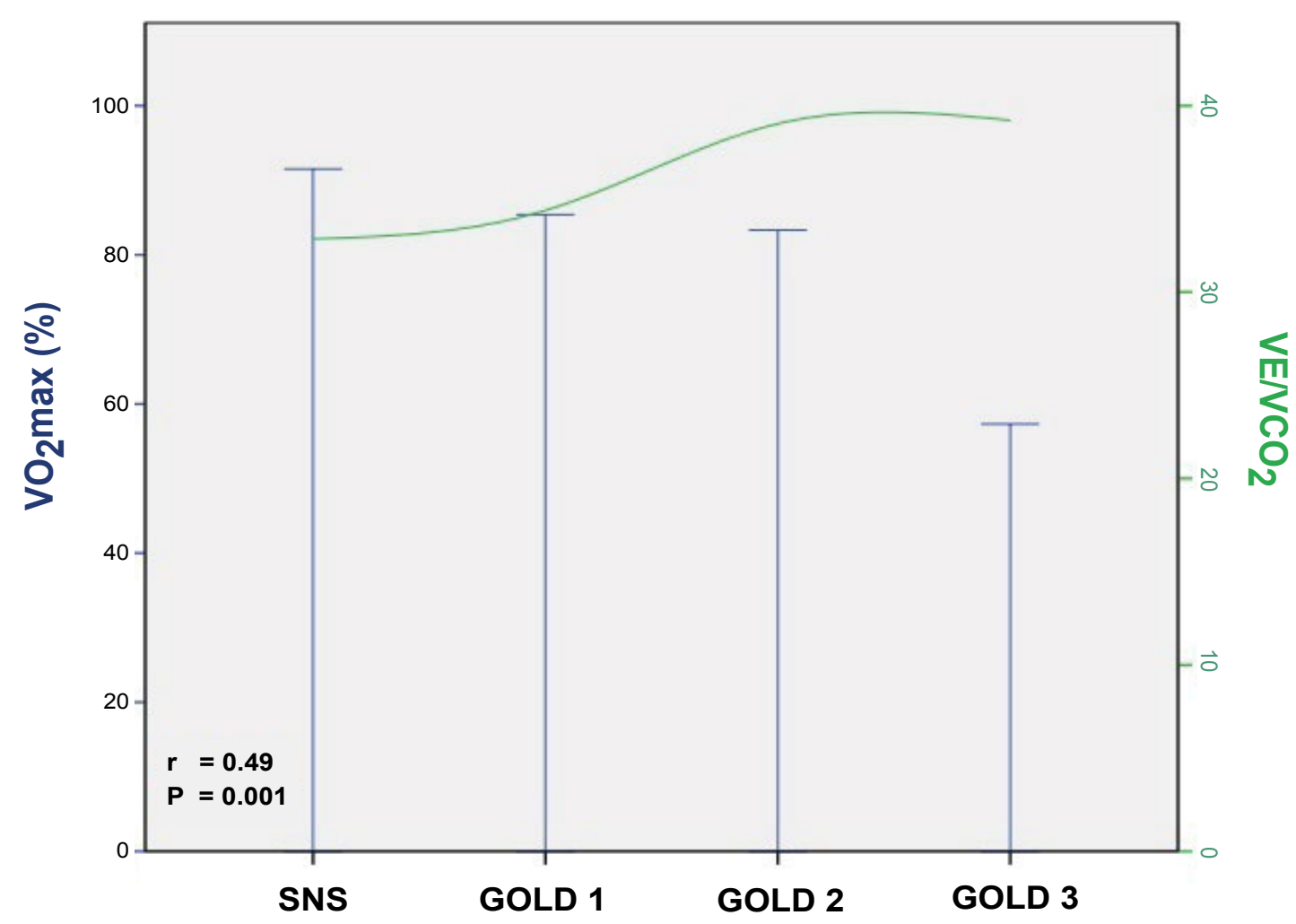

Figure 3a Correlation between the increased ve/ $\mathrm{vco}_{2}$ over maximal oxygen consumption ( $\mathrm{vo}_{2} \mathrm{max}$ ) in studied patients. 


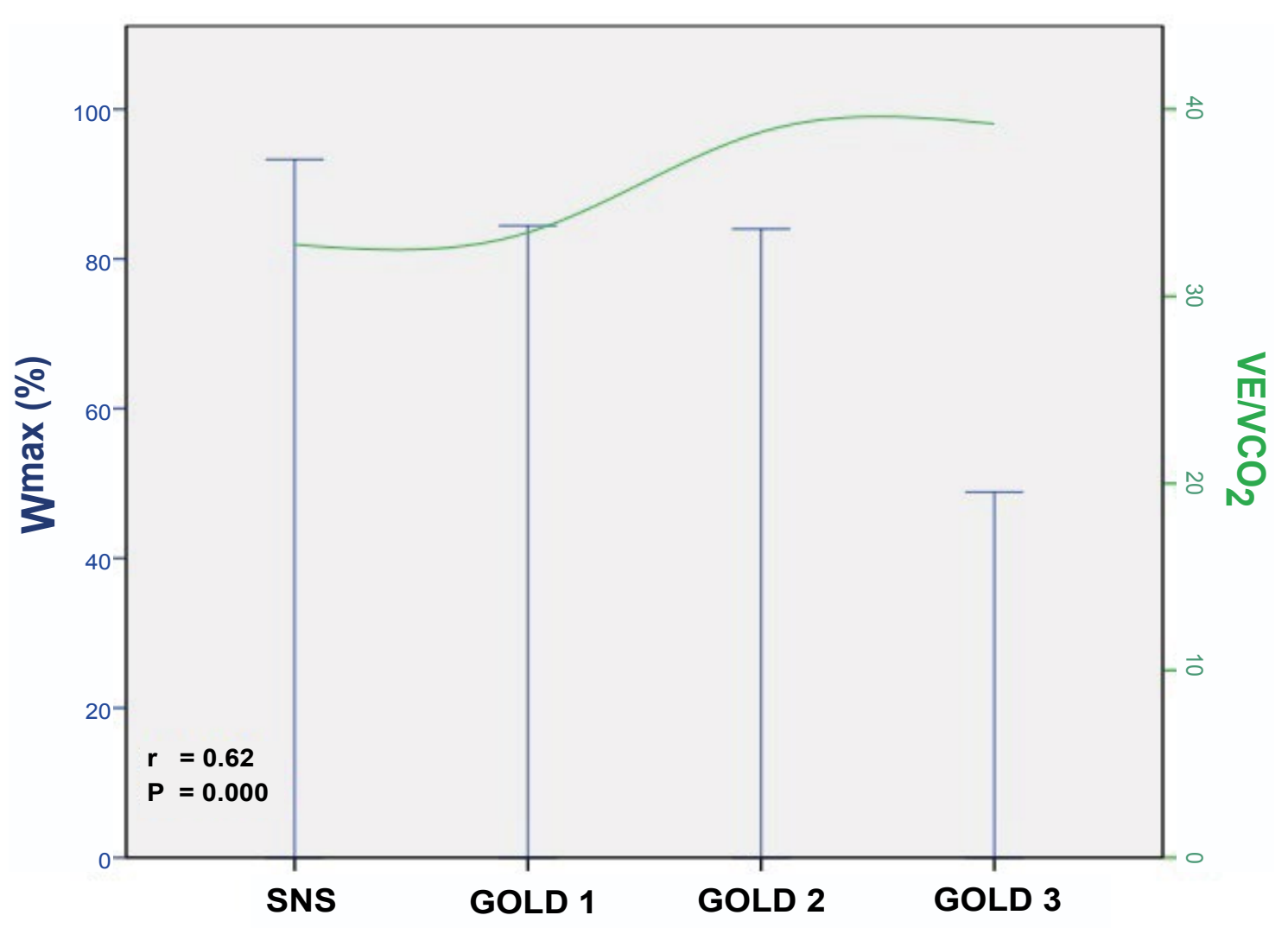

Figure 3b Correlation between the increased ve/ $\mathrm{vco}_{2}$ over maximal power (wmax) in studied patients.

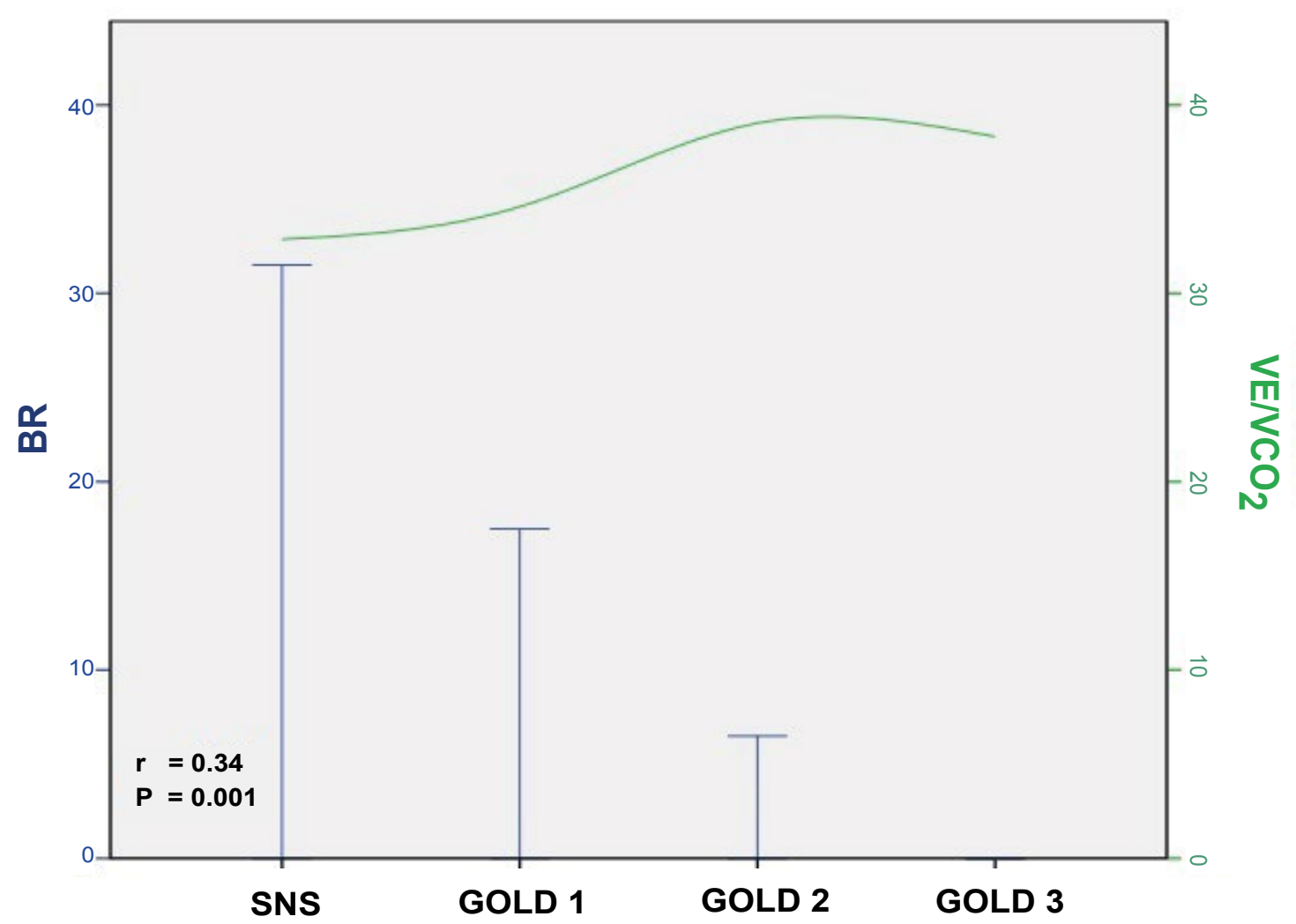

Figure 3c Correlation between the increased ve/ $/ \mathrm{coO}_{2}$ over breathing reserve (br) in studied patients. 
the studied patients exercise test ended due to dyspnea and leg fatigue. They used a large part of their breathing reserves and presented a severe increase of VE/VCO, measured at ventilatory threshold, to exclude the influence of voluntary effort.

The increase of VE/VCO is indicative of ventilatory inefficiency [3-5,27-29]. The inverse relationship between VE/VCO and the decrease in VO max and $W$, and particularly $V O /$ hearth rate and CP in patients with VE/VCO over 34, addresses the participation of this mechanism in limiting exercise capacity in patients with pulmonary emphysema with mild to severe COPD [30] (Table 3).

In this regard, we propose that ventilatory inefficiency can be an independent contribution to pathophysiology of exercise limitation in pulmonary emphysema, as was suggested by multiple regression analysis. Patients with pulmonary emphysema, with spirometric severity corresponding to GOLD 1-3 presented increased VE/VCO, severe expiratory flow limitation and the half of them had dynamic hyperinflation, moreover in multiple regression models the independent variable VE/VCO was the only which demonstrate statistical significance over the exercise variables VO and W (Table 4).

Our observations allows consider some influence of ventilatory inefficiency on systolic volume on pulmonary emphysema (represented by the surrogate parameter VO/heart rate) [31,32] and also the cardiac power, represented by the surrogate parameter CP $[29,30]$. These aspects links an involvement of cardiocirculatory function in COPD patients, due to a progressive impairment of right ventricular function or impairment in venous return, but a specific cardiac abnormality has not been established [29-32]. We demonstrated that ventilatory inefficiency increases with the severity of pulmonary emphysema, and consequently the resulting enhanced ventilatory demand reduced the BR. By this

Table 3 Influence of ventilatory inefficiency over the evaluated parameters in studied patients.

\begin{tabular}{|c|c|c|c|}
\hline & $\mathrm{VE} / \mathrm{VCO}_{2}$ & $\mathbf{r}$ & $\mathbf{P}$ \\
\hline $\mathrm{VO}_{2} \max (\%$ of reduction) & $-1.82(-2.66$ to -0.98$)$ & 0.487 & 0.001 \\
\hline $\mathrm{VO}_{2 \max } / \mathrm{Kg}$ (\% of reduction) & $-0.63(-0.10$ to -0.35 & 0.495 & 0.000 \\
\hline Wmax (\% of reduction) & $-2.94(-3.91$ to -1.80$)$ & 0.621 & 0.000 \\
\hline EFL (\% of increase) & 4.83 (3.78 to 6.12 ) & 0.625 & 0.000 \\
\hline$\Delta \mathrm{IC}(\mathrm{L})$ & 0.03 (0.01 to 0.05$)$ & 0.378 & 0.014 \\
\hline BR (\% of reduction) & $-1.32(-2.29$ to -0.11$)$ & 0.341 & 0.028 \\
\hline${ }^{*} \mathrm{VO}_{2} /$ heart rate (\% of reduction) & $-2.14(-3.80$ to -0.46$)$ & 0.383 & 0.037 \\
\hline${ }^{*} \mathrm{CP}$ (Units of reduction) & $-557(-931$ to -131$)$ & 0.448 & 0.019 \\
\hline
\end{tabular}

Values are presented as the mean +/- SD, and were expressed as reduction or increase.

$r$ : $r$ value between $\mathrm{VE} / \mathrm{VCO}_{2}$ over the evaluated parameter.

$\mathrm{P}$ : $\mathrm{P}$ value between $\mathrm{VE} / \mathrm{VCO}_{2}$ over the evaluated parameter.

* Determined in patients with a cut point of $\mathrm{VE} / \mathrm{VCO}_{2}>34$

$\mathrm{VO}_{2}$ max: maximum oxygen consumption, $\mathrm{VO}_{2} \max / \mathrm{Kg}$ : $\mathrm{VO}_{2}$ max per $\mathrm{Kg}$ of weight, Wmax: maximum Power, EFL: expiratory flow limitation, $\triangle \mathrm{IC}$ decrease in Inspiratory Capacity, BR: Breathing reserve, $\mathrm{VO}_{2} /$ heart rate: Oxygen pulse, CP: Circulatory power.
Table 4 Models of multiple regression including the independent variables body mass index, expiratory flow limitation, decrease in inspiratory capacity and ve/ $\mathrm{vCO}_{2}$, over the response variables $\mathrm{vo}_{2} \max$, wmax in studied patients.

\begin{tabular}{|c|c|c|c|c|c|}
\hline & $\begin{array}{l}\text { Model of } \\
\text { multiple } \\
\text { regression } \\
\text { ( } \mathrm{r} / \mathrm{P} \text { value) }\end{array}$ & $\begin{array}{c}\text { BMI } \\
\text { (P value) }\end{array}$ & $\begin{array}{c}\text { EFL } \\
\text { (P value) }\end{array}$ & $\begin{array}{c}\Delta I C \\
\text { (P value) }\end{array}$ & $\begin{array}{l}\text { VE/VCO } \\
\text { (P value) }\end{array}$ \\
\hline $\begin{array}{l}\text { Response } \\
\text { variable } \\
\mathrm{VO}_{2} \max \end{array}$ & $0.547 / 0.019$ & 0.362 & 0.654 & 0.716 & 0.034 \\
\hline $\begin{array}{c}\text { Response } \\
\text { variable } \\
\text { Wmax }\end{array}$ & $0.629 / 0.004$ & 0.975 & 0.670 & 0.526 & 0.024 \\
\hline
\end{tabular}

In models of multiple regression including the influence of the independent variables $\mathrm{BMI}, \mathrm{EFL}, \triangle \mathrm{IC}$, and $\mathrm{VE} / \mathrm{VCO}_{2}$, over the response continuous variables $\mathrm{VO}_{2}$ and $\mathrm{W}$, only the independent variable $\mathrm{VE} / \mathrm{VCO}_{2}$ showed statistical significance $(P=0.034$ and 0.024$)$

$B M I$ : Body mass index, EFL: expiratory flow limitation, $\triangle \mathrm{IC}$ : decrease in inspiratory capacity.

means and other insufficiently described mechanisms, ventilatory inefficiency reduces exercise capacity, and the influence of this mechanism into boosts expiratory flow limitation deserves recognition. Interestingly we have detected an increased VE/ $\mathrm{CO}$, and reduction in $\mathrm{BR}$ in patients with pulmonary emphysema, with spirometric severity corresponding to GOLD 1, suggesting that ventilatory inefficiency could be an initial manifestation of lung damage in this disease.

Limitations of our study include lack of arterial blood gases for every patient. Also recently, studies comparing patients with either dominant emphysema or chronic bronchitis with VEF1 measured by Spirometry and Body Plethismography, have challenged GOLD classification on COPD, by demonstrating relevant changes in patients' classification, which may mislead severity and prognosis [33]. A significant proportion of our patients were obese, yet studies have not demonstrated so far a significant reduction on exercise capacity in obese patients with COPD; therefore we consider that this does not affect our results. In the design we did not have the capability to perform quantitative images of the lung by $\mathrm{CT}$ to improve the analysis. Nevertheless, future research is needed to clarify the influence of ventilatory inefficiency on the exercise response in COPD [34,35], and its importance as a prognostic factor on COPD.

\section{Conclusion}

An increased VE/VCO means ventilatory inefficiency to clear CO. In this study an increased VE/VCO was seen in patients with pulmonary emphysema in parallel with the spirometric severity, according with GOLD classification, and was correlated with a decreased exercise capacity, independent of hyperinflation in models of multiple regression. Patients with a marked increase on VE/VCO, also presented a significant reduction of surrogate parameters of cardiac function as systolic volume and cardiac power. 


\section{References}

1 Loring SH, García-Jacques M, Malhotra A (2009) Pulmonary characteristics in COPD and mechanisms of increased work of breathing. J Appl Physiol 107: 309-314.

2 Calverley PM, Koulouris NG (2005) Flow limitation and dynamic hyperinflation: key concepts in modern respiratory physiology. Eur Respir J 25: 186-199.

3 Neder JA, O'Donnell CD, Cory J, Langer D, Ciavaglia CE, et al. (2015) Ventilation Distribution Heterogeneity at Rest as a Marker of Exercise Impairment in Mild-to-Advanced COPD. COPD 12: 249-256.

4 Elbehairy AF, Ciavaglia CE, Webb KA, Guenette JA, Jensen D, et al. (2015) Pulmonary Gas Exchange Abnormalities in Mild Chronic Obstructive Pulmonary Disease. Implications for Dyspnea and Exercise Intolerance. Am J Respir Crit Care Med 191: 1384-1394.

5 Caviedes IR, Delgado I, Soto R (2012) Ventilatory inefficiency as a limiting factor for exercise in patients with COPD. Respir Care 57: 583-589.

6 Torchio R, Guglielmo M, Giardino R, Ardissone F, Ciacco C, et al. (2010) Exercise ventilatory inefficiency and mortality in patients with chronic obstructive pulmonary disease undergoing surgery for nonsmall-cell lung cancer. Eur J Cardiothorac Surg 38: 14-19.

7 Weisman IM, Beck KC, Casaburi R, Cotes JE, Crapo RO, et al. (2003) American Thoracic Society/American College of Chest Physicians. ATS/ACCP statement on cardiopulmonary exercise test. Am J Respir Crit Care Med 167: 211-277.

8 Palange P, Ward SA, Carlsen KH, Casaburi R (2007) Recommendations on the use of exercise testing in clinical practice. Eur Respir J 29: 185209.

9 Woods PR, Olson TP, Frantz RP, Johnson BD (2010) Causes of Breathing inefficiency during exercise in hearth failure. J Card Fail 16: 835-842.

10 Lange P, Marott JL, Vestbo J, Olsen KR, Ingebrigtsen TS, et al. (2012) Prediction of the clinical course of chronic obstructive pulmonary disease, using the new GOLD classification: a study of the general population. Am J Respir Crit Care Med 186: 975-981.

11 Foster WL, Pratt PC, Roggli VL, Godwin JD, Halvorsen RA, et al. (1986) Centrilobular emphysema: CT-pathologic correlation. Radiology 159: 27-32.

12 Wasserman K (1997) Diagnosing cardiovascular and lung pathophysiology from exercise gas Exchange. Chest 112: 1091-1101.

13 Jones NL, Makrides L, Hitchcock C, Chypchar T, McCartney N (1985) Normal standards for an incremental progressive cycle ergometer test. Am Rev Respir Dis 131: 700-708.

14 Jones NL, Summers E, Killian KJ (1989) Influence of age and stature on exercise capacity during incremental cycle ergometry in men and women. Am Rev Respir Dis 140: 1373-1380.

15 Johnson B, Weisman IM, Zeballos J, Beck K (1999) Emerging concepts in the evaluation of ventilatory limitation during exercise. The exercise tidal flow-volume loop. Chest 116: 488-503.

16 O'Donnell DE, Revill SM, Webb KA (2001) Dynamic hyperinflation and exercise intolerance in chronic obstructive pulmonary disease. Am J Respir Crit Care Med 164: 770-777.

17 Cohen-Solal A, Tabet JY, Logeart D, Bourgoin P, Tokmakova M, et al. (2002) A non-invasively determined surrogate of cardiac power ('circulatory power') at peak exercise is a powerful prognostic factor in chronic heart failure. Eur Heart J 23: 806-814.

18 Fleg JL, Piña IL, Balady GJ, Chaitman B, Fletcher B, et al. (2000) Assessment of functional capacity in clinical and research applications. An advisory from the committee on exercise, rehabilitation, and prevention, council on clinical cardiology, American Heart Association. Circulation 102: 1591-1597.

19 Nicholls DP, O'Dochartaigh C, Riley MS (2002) Circulatory power, a new perspective on an old friend. Eur Heart J 23: 1242-1245.

20 Tumminello G, Guazzi M, Lancellotti P, Pierard LA (2007) Exercise ventilation inefficiency in hearth failure: pathophysiological and clinical significance. Eur Heart J 28: 673-678.

21 Gitt AK, Wassermann K, Kilowski C, Kleemann T, Kilkowski A, et al. (2002) Exercise anaerobic threshold and ventilatory efficiency identify heart failure patients for high risk of early death. Circulation 106: 3079-3084.

22 Baril J, De Souza M, Leroy D, Ofir D, Aguilaniu B, et al. (2006) Does dynamic hyperinflation impair submaximal exercise cardiac output in chronic obstructive pulmonary disease? Clin Invest Med 29: 104-109.

23 Pinto Plata V, Celli-Cruz R, Vassaux C, Torre-Bouscoulet L, Mendes A, et al. (2007) Differences in cardiopulmonary exercise test results by American Thoracic Society/European Respiratory Society global initiative for chronic obstructive lung disease stage categories and gender. Chest 132: 1204-1211.

24 Callens E, Graba S, Gillet-Juvin K, Essalhi M, Bidaud-Chevalier B, et al. (2009) Measurement of Dynamic hyperinflation after a 6 minute walk test in patients with COPD. Chest 136: $1466-1472$.

25 Hannink JD, Van Helvoort HA, Dekhuijzen PN, Heijdra YF (2010) Dynamic hyperinflation during daily activities: does COPD global initiative for chronic obstructive lung disease stage matter? Chest 137: $1116-1121$.

26 Casanova C, Cote C, De Torres JP, Aguirre-Jaime A, Marin JM, et al. (2005) Inspiratory to total lung capacity ratio predicts mortality in patients with chronic obstructive pulmonary disease. Am J Respir Crit Care Med 171: 591-597.

27 Mejhert M, Linder-Klingsell E, Edner M, Kahan T, Persson H (2002) Ventilatory variables are strong prognostic markers in elderly patients with hearth failure. Heart 88: 239-243.

28 Ponikowski P, Francis DP, Piepoli MF, Davies LC, Chua TP, et al. (2001) Enhanced ventilatory response to exercise in patients with chronic heart failure and preserved exercise tolerance. Marker of abnormal cardiorespiratory reflex control and predictor of poor prognosis. Circulation 103: 967-972.

29 Methvin AB, Owens AT, Emmi AG, Allen M, Wiegers SE, et al. (2012) Ventilatory inefficiency reflects right ventricular dysfunction in systolic hearth failure. Chest 139: 617-625.

30 Vassaux C, Torre-Bouscoulet L, Zeineldine S, Cortopassi F, Paz- Diaz $\mathrm{H}$, et al. (2008) Effects of hyperinflation on the oxygen pulse as a marker of cardiac performance in COPD. Eur Respir J 32: 1275-1282.

31 Scharf C, Merz T, Kiowski W, Oechslin E, Schalcher C, et al. (2002) Noninvasive assessment of cardiac pumping capacity during exercise predicts prognosis in patients with congestive heart failure. Chest 122: $1333-1339$.

32 Williams SG, Cooke GA, Wright DJ, Parsons WJ, Riley RL, et al. (2001) Peak exercise cardiac power output. A direct indicator of cardiac 
function strongly predictive of prognosis in chronic heart failure. Eur Heart J 22: 1496-1503.

33 Pellegrino R, Crimi E, Gobbi A, Torchio R, Antonelli A, et al. (2015) Severity grading of chronic obstructive pulmonary disease: the confounding effect of phenotype and thoracic gas compression J Appl Physiol 118: 796-802.
34 Ora J, Laveneziana P, Wadell K, Preston M, Webb K, et al. (2011) Effect of obesity on respiratory mechanics during rest and exercise in COPDJ. Appl Physiol 111: 10-19.

35 O' Donnell D, Ciavaglia C, Neder A (2014) When Obesity and Chronic Obstructive Pulmonary Disease Collide. Physiological and Clinical Consequences. Ann Am Thorac Soc 11: 635-644. 